\title{
The Influence of n-3 Polyunsaturated Fatty Acids and Very Low Calorie Diet during a Short-term Weight Reducing Regimen on Weight Loss and Serum Fatty Acid Composition in Severely Obese Women
}

\author{
M. KUNEŠOVÁ ${ }^{1,2}$, R. BRAUNEROVÁ ${ }^{1}$, P. HLAVATÝ ${ }^{1,2}$, E. TVRZICKÁ ${ }^{3}$, \\ B. STAŇKOVÁ ${ }^{3}$, J. ŠKRHA ${ }^{2}$, J. HILGERTOVÁ ${ }^{2}$, M. HILL ${ }^{1}$, J. KOPECKÝ ${ }^{4}$, \\ M. WAGENKNECHT ${ }^{1}$, V. HAINER ${ }^{1}$, M. MATOULEK ${ }^{2}$, J. PAŘIZZKOVÁ ${ }^{1}$, \\ A. ŽÁK ${ }^{3}, \breve{S}$. SVAČINA ${ }^{2}$
}

${ }^{1}$ Obesity Management Center, Institute of Endocrinology, ${ }^{2}$ Third Department of Internal Medicine, ${ }^{3}$ Fourth Department of Internal Medicine, First Medical Faculty, Charles University, and ${ }^{4}$ Institute of Physiology, Academy of Sciences, Prague, Czech Republic

Received February 21, 2005

Accepted March 11, 2005

On-line available April 26, 2005

\begin{abstract}
Summary
Polyunsaturated fatty acids of n-3 series (n-3 PUFA) were shown to increase basal fat oxidation in humans. The aim of the study was to compare the effect of n-3 PUFA added to a very low calorie diet (VLCD), with VLCD only during three-week inpatient weight reduction. Twenty severely obese women were randomly assigned to VLCD with n-3 PUFA or with placebo. Fatty acids in serum lipid fractions were quantified by gas chromatography. Differences between the groups were determined using ANOVA. Higher weight (7.55 \pm 1.77 vs. $6.07 \pm 2.16 \mathrm{~kg}$, NS), BMI (2.82 \pm 0.62 vs. $2.22 \pm 0.74, \mathrm{p}<0.05)$ and hip circumference losses $(4.8 \pm 1.81$ vs. $2.5 \pm 2.51 \mathrm{~cm}, \mathrm{p}<0.05)$ were found in the $n-3$ group as compared to the control group. Significantly higher increase in beta-hydroxybutyrate was found in the $n-3$ group showing higher ketogenesis and possible higher fatty acid oxidation. The increase in beta-hydroxybutyrate significantly correlated with the increase in serum phospholipid arachidonic acid $(20: 4 n-6 ; r=0.91, p<0.001)$. In the $n-$ 3 group significantly higher increase was found in n-3 PUFA (eicosapentaenoic acid, 20:5n-3, docosahexaenoic acid, 22:6n-3) in trigycerides and phospholipids. The significant decrease of palmitoleic acid (16:1n-7) and vaccenic acid (18:1n-7) in triglycerides probably reflected lower lipogenesis. A significant negative correlation between BMI change and phospholipid docosahexaenoic acid change was found $(r=-0.595, p<0.008)$. The results suggest that long chain $n-3$ PUFA enhance weight loss in obese females treated by VLCD. Docosahexaenoate (22:6n-3) seems to be the active component.
\end{abstract}

Key words

Obesity treatment $\bullet$ Fatty acid composition $\bullet$ Very low calorie diet $\bullet$ Beta-hydroxybutyrate $\bullet$ PUFA 


\section{Introduction}

Caloric restriction and weight loss are responsible for a modification of gene expression in adipose tissue while the proportion of dietary fat does not seem to be decisive (Arvidson et al. 2004, Viguerie et al. 2005). Composition of dietary fat has been shown to modify the effect of weight reducing diets (Kriketos et al. 2001, Clifton et al. 2004). Reducing the energy intake tends to dilute the changes in membrane phospholipid fatty acid composition reflecting dietary fat composition in rats (Cha and Jones 2000).

In moderately obese women we have previously found a significant increase of phospholipid palmitic acid (16:0) and significant decrease of linoleic acid (18:2n-6) and dihomo-gamma-linolenic acid (20:3n-6) after very low calorie diet (VLCD) (Kunešová et al. 2002a). In humans adipose alpha-linolenic acid was permanently reduced during VLCD (Phinney et al. 1990). In rats, linoleic and alpha-linolenic acids (18:3n-3) were shown to be rapidly beta-oxidized even under conditions of extreme dietary linoleate deficiency (Cunnane et al. 1998). Moreover, enhanced recycling of carbon from linoleic and alpha-linolenic acid to palmitic acid was suggested (Cunnane et al. 2003). The conversion of linoleic and alpha-linolenic acids to long chain polyunsaturated acids was shown to be a quantitatively minor route of utilization in healthy women (McCloy et al. 2004). The composition of fatty acids in serum lipids and adipose tissue triglycerides reflects the composition of fatty acids in dietary fats. Fatty acid composition in skeletal muscle triglycerides and phospholipids correlates with parameters of insulin resistance and with the risk of type 2 diabetes (Vessby et al. 1994a). Positive association of arachidonic acid (20:4n-6, AA) in serum and muscle phospholipids with insulin sensitivity was shown (Pelikánová et al. 1989, Borkman et al. 1993). Inverse association between insulin sensitivity and serum dihomo-gamma-linolenic acid (20:3n-6, DHGLA) found by Vessby et al. (1994b) and Lovejoy et al. (2001) reflects higher activity of delta-5 desaturation of DHGLA to AA (Felton et al 2004). High ratios of linoleic to arachidonic acid concentrations have been observed in subjects with insulin resistance (Berry 2001).

Long chain n-3 PUFA enhance lipid oxidation in healthy humans (Delarue et al. 1996, Couet et al. 1997). In animals, addition of n-3 fatty acids led to a preferential loss of epididymal fat (Raclot et al. 1997) associated with decreased cellularity (Růžičková et al. 2004). We have previously reported a strong genetic influence on the composition of serum and adipose tissue lipids under basal conditions in monozygotic twins (Kunešová et al. 2002b), after a short-term weight reduction regimen and after one-year of weight stabilization (Kunešová et al. 2002a). After the weight loss the consistent intra-pair resemblances for $n-3$ fatty acids were found despite dietary stress induced by a very low calorie diet, indicating that the conservation and distribution of this family of essential fatty acids is subject to considerable genetic variance in humans. The resemblances were not influenced by differences in the diet. This was shown when comparing twins concordant and discordant in fat intake.

The present study shows the effect of a shortterm inpatient weight-reducing regimen consisting of a very low calorie diet (VLCD) and long chain n-3 PUFA as compared to weight-reducing regimen with VLCD only in severely obese women.

\section{Methods}

\section{Subjects}

Twenty severely obese women were randomly assigned to a very low calorie diet with n-3 PUFA supplement (n-3 VLCD) or with saline solution (VLCD). There were no significant differences between groups in basal BMI (n-3 VLCD 40.60 \pm 4.05 ; VLCD 45.14 \pm 6.9 $\mathrm{kg} / \mathrm{m}^{2}$ ) and age (n-3 VLCD 54.27 \pm 5.36 ; VLCD $49.78 \pm$ 12.35 years). The study was approved by the Charles University Medical Ethical Committee.

\section{Design of the study}

The regimen consisted of a one-week eucaloric outpatient baseline stabilization period followed by three weeks of inpatient weight reducing period. During the baseline week and last 3 days of the inpatient stay the subjects did not change their weight. Weight reducing regimen consisted of VLCD Redita ${ }^{\mathrm{R}}$ (Promil Nový Bydžov, Czech Republic) providing 2200kJ/day, comprised of $40 \mathrm{~g}$ protein, $70 \mathrm{~g}$ carbohydrates and $9 \mathrm{~g}$ fat, with addition of n-3 highly unsaturated fatty acids 2.8 g/day (Omega 3 Forte $^{\mathrm{R}}$, SVUS Pharma, Hradec Kralove, CzR), (n-3 VLCD) or VLCD with saline solution (VLCD group). Supplement with n-3 consisted of eicosapentaenoic acid (EPA) and docosahexaenoic acid (DHA) in ratio 2:1, vitamin E $0.9 \mathrm{mg} / 500 \mathrm{mg}$ capsule was added to prevent fatty acid peroxidation. The reduction regimen included also daily light to moderate 
physical activity lasting about $60 \mathrm{~min} /$ day. Compliance to the diet was tested by daily semiquantitative measurement of urine ketone bodies and adherence to the physical training by pedometers (Hainer et al. 2000). All these procedures were undertaken in the Third Department of Internal Medicine, Charles University in Prague. At the beginning of the weight reducing regimen and on the day 3, 7, and 21 of fasting blood was withdrawn for determination of beta-hydroxybutyrate, free fatty acids, total cholesterol, HDL-cholesterol, triglycerides, fasting blood glucose, fasting insulin, superoxide dismutase, malonyldialdehyde, $\mathrm{C}$ and $\mathrm{E}$ vitamins. Laboratory analyses were performed by routine laboratory methods. Serum beta-hydroxybutyrate was assessed fluorimetrically (Olsen 1971) and non-esterified free fatty acids were determined photometrically (Duncombe 1964).

At baseline and on day 21, serum lipid fraction of fatty acid analysis was carried out (serum phospholipids - PL, triglycerides - TG and cholesteryl esters - CE); at the same time abdominal adipose tissue was also obtained by needle biopsy. Analysis of the results from adipose tissue samples will be reported elsewhere. Proteins of acute phase fibrinogen, C-reactive protein, $\alpha_{1}$ antitrypsin, orosomukoid, $\alpha_{2}$ macroglobulin, transferrin and prealbumin were also assessed by routine laboratory methods.

\section{Body composition and regional tissue distribution}

Anthropometric estimation of body fat was performed by measurement of ten skinfolds according to Pařízková (1977) and of four skinfolds according to Durnin and Wommersley (1974). Waist and hip circumference and sagittal abdominal diameter at the level L4/5 were measured following the standardized procedure recommended at the Airlie Conference (Lohman et al. 1989). Body fat content was estimated by bioelectrical impedance measurement (Tanita TBF 105, Japan).

\section{Fatty acid composition}

Fatty acid composition of serum lipids was performed by gas chromatography after separation of individual serum fractions by thin-layer chromatography on silica gel. Detailed description of the method is given elsewhere (Tvrzická et al. 2002).

\section{Statistical methods}

Relationships between one dependent variable and the set of independent variables were evaluated using a stepwise backward multiple regression. Prior to the analysis, the original dependent variables were transformed by power transformation using a normal probability plot for finding the best transformations. The minimum value of the mean squared error of the linear regression fit between theoretical fractiles of the Gaussian distribution and experimental fractiles indicated the optimum transformation parameter. Severe nonhomogeneities as detected using the aforementioned plot were not included in the finding of the optimum transformation parameters. Nevertheless, these outliers were included in further processing. The optimum transformation of the dependent variable was searched using the minimum skewness of Studentized residuals of the multiple regression model as an indicator. Further regression diagnostics was performed as described elsewhere (Meloun et al. 2002, 2004). The relationships between two variables were estimated using Pearson's correlations. Respecting a non-Gaussian distribution and a non-constant variance in some variables, these were transformed prior to testing as described above. For transformation strategy see also our previous study (Meloun et al. 2000). The effects of status (patients, controls) and stage of the treatment (before treatment, after treatment) and a between-factor interaction were evaluated using a repeated measures ANOVA model. Again, respecting the non-Gaussian data distribution in some variables, such data underwent power transformations. The transformation strategy as well as the residual analysis was analogous as in the regression.

The results tested by the aforesaid ANOVA model were checked by non-parametric tests of the differences between the beginning and end of the treatment. The significances of the differences were evaluated using Wilcoxon's paired test. To estimate how the differences diverged between controls and patients, the Mann-Whitney test of their means was applied.

Data are expressed as means \pm S.E.M. $\mathrm{P}=0.05$ was taken as the threshold of statistical significance.

\section{Results}

Baseline characteristics of the subjects before the treatment and the effect of the treatment are presented in Table 1. Weight loss (7.55 \pm 1.77 vs. $6.07 \pm 2.16 \mathrm{~kg}$, $\mathrm{p}<0.10)$ and BMI decrease $(2.82 \pm 0.62$ vs. $2.22 \pm 0.74$ $\left.\mathrm{kg} / \mathrm{m}^{2}, \quad \mathrm{p}<0.05\right)$ were higher in the $\mathrm{n}-3$ PUFA supplemented group. The decrease of hip circumference 
was significantly higher after n-3 VLCD $(4.8 \pm 1.81 \mathrm{~cm})$ than in the VLCD $(2.5 \pm 2.51 \mathrm{~cm}, \mathrm{p}<0.05)$ group. Higher increase in beta-hydroxybutyrate was found in $n-3$ group $(\mathrm{p}<0.01$, Fig. 1A). A tendency to higher decrease in fibrinogen was observed in $n-3$ group ( $<<0.09$, Fig. 1B).
A

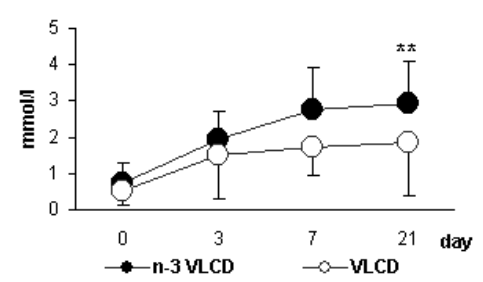

B

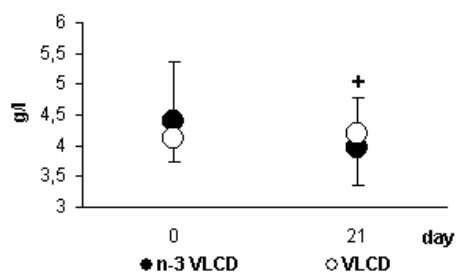

Fig. 1. A. Change in serum beta-hydroxybutyrate during the weight-reducing regimen $* * p<0.01$. B. Change in serum fibrinogen during the weight-reducing regimen $+\mathrm{NS}(\mathrm{p}<0.09)$, Values are expressed as mean \pm S.D.
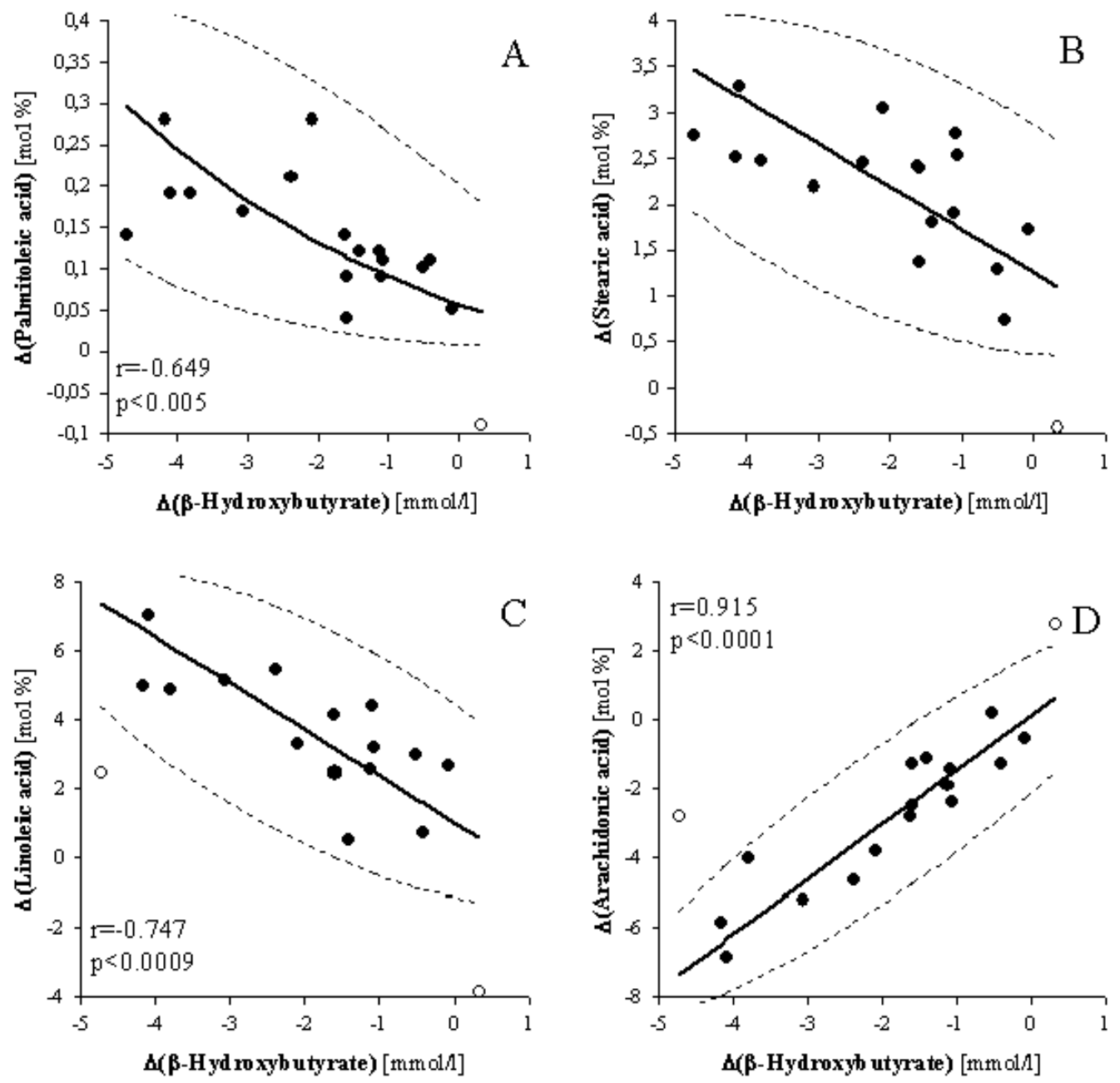

Fig. 2. Correlation of the change in beta-hydroxybutyerate and change in palmitoleic acid (16:1n-7) (A), change in stearic acid (18:0) (B), change in linoleic acid (18:2n-6) (C), change in arachidonic acid (20:4n-6) (D). Pearson's correlations between the change of betahydroxybutyrate and change in proportion of individual fatty acids in serum phospholipids. The full and empty circles indicate the individual subjects included in the analysis and outliers, respectively. The full and dashed curves indicate the retransformed principal axes and their $95 \%$ confidence ellipsoids (the area in which the $95 \%$ of the experimental points should be theoretically found provided that no outliers are present), respectively. Respecting the non-Gaussian data distribution and the non-constant variance the data were transformed using a power transformation prior analysis (for details see Statistical data treatment). The symbols $r$ and $p$ represent the correlation coefficients and their statistical significances when correlating the transformed data. 

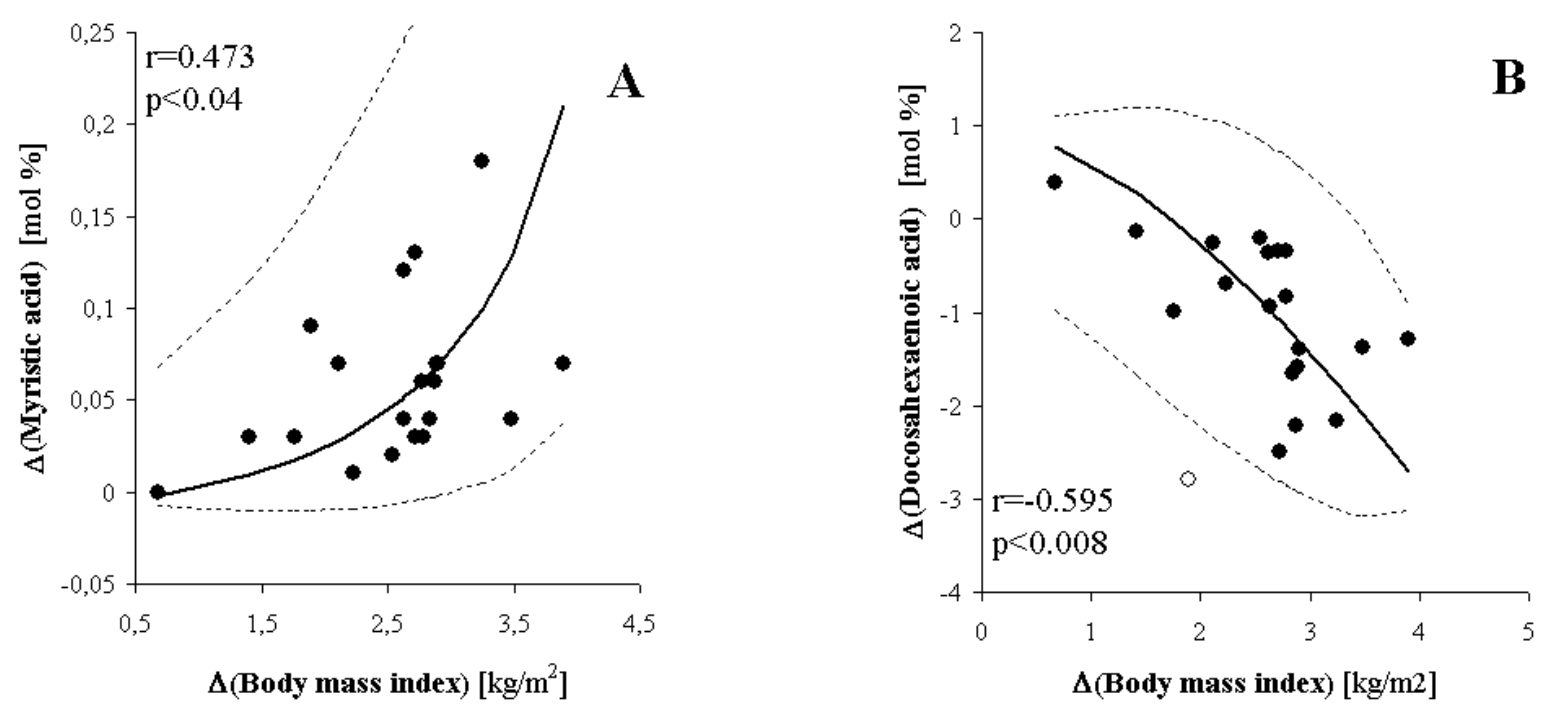

Fig. 3. Pearson's correlations between the change of BMI and change in proportion of myristic acid (14:0) (A) and docosahexaenoic acid $(20: 6 n-3)$ (B). For comments see Fig. 2.

Table 1. Characteristics of the group before the treatment and the effect of the weight-reducing regimen

\begin{tabular}{lll}
\hline Variable & $\begin{array}{l}\text { N3 VLCD } \\
(\mathbf{n}=\mathbf{1 1})\end{array}$ & $\begin{array}{l}\text { VLCD } \\
(\mathbf{n}=\mathbf{9})\end{array}$ \\
\hline $\begin{array}{l}\text { Initial values } \\
\text { Age (years) }\end{array}$ & $54.27 \pm 5.36$ & $49.78 \pm 12.35$ \\
Weight $(\mathrm{kg})$ & $108.2 \pm 8.7$ & $123.2 \pm 23.7$ \\
BMI $\left(\mathrm{kg} / \mathrm{m}^{2}\right)$ & $40.60 \pm 4.05$ & $45.14 \pm 6.9$ \\
Waist $(\mathrm{cm})$ & $116.2 \pm 10.0$ & $119.4 \pm 11.6$ \\
Hip $(\mathrm{cm})$ & $136.0 \pm 7.8$ & $140.4 \pm 13.1$ \\
Effect of treatment & & \\
Weight loss $(\mathrm{kg})$ & $7.55 \pm 1.77$ & $6.07 \pm 2.16 * *$ \\
BMI loss $\left(\mathrm{kg} / \mathrm{m}^{2}\right)$ & $2.82 \pm 0.62$ & $2.22 \pm 0.74 *$ \\
Waist $(\mathrm{cm})$ & $5.5 \pm 1.71$ & $3.3 \pm 3.41$ \\
Hip $(\mathrm{cm})$ & $4.8 \pm 1.81$ & $2.5 \pm 2.51 *$ \\
\hline
\end{tabular}

$* p<0.05 * *$ NS $(p<0.1)$, Values are expressed as mean \pm S.D.

Table 2 shows the composition of fatty acids in serum phospholipids (PL) and triglycerides (TG) before treatment and after the treatment in the n-3 VLCD and VLCD groups. An increase in eicosapentaenoic (EPA, 20:5n-3) and docosahexaenoic acids (DHA, 22:6n-3) in both PL and TG was found. In TG a significantly higher decrease of palmitoleic (16:1n-7, POA) and vaccenic (18:1n-7) acids and significantly higher increase of oleic acid (18:1n-9) was observed. Palmitoleate was shown as a marker of lipogenesis previously (Fukuda et al. 1999, Kunešová et al. 2002b). A highly significant negative correlation between changes in levels of betahydroxybutyrate and in serum POA proportions in PL $(\mathrm{p}=-0.83, \mathrm{p}<0.0001)$, TG and CE $(\mathrm{r}=-0.69, \mathrm{p}<0.005$, $\mathrm{r}=-0.49, \mathrm{p}<0.05)$ respectively, could indicate a higher level of hepatic beta-oxidation. However, it could also suggest a lower lipogenesis. Negative correlation between initial BMI and change in POA was found $(r=-0.45$, $\mathrm{p}<0.05)$.

A higher decrease of TG POA was shown in the n-3 VLCD treated group. A higher hepatic beta-oxidation in response to $n-3$ supplement could be inferred by a higher increase of beta-hydroxybutyrate in n-3 treated group. Significantly higher increase in TG oleic acid (18:1n-9, OA) in n-3 VLCD was shown. A strong positive correlation was observed between the change of PL, TG and CE arachidonic acid and the change of betahydroxybutyrate $(\mathrm{r}=0.92, \mathrm{p}<0.001 ; \mathrm{r}=0.68, \mathrm{p}<0.005$; $\mathrm{r}=0.66, \mathrm{p}<0.005$, respectively); significant negative correlation of beta-hydroxybutyrate change with change of palmitic (16:0), stearic (18:0) and linoleic (18:2n-6) acids in phospholipids was also shown (Fig. 2). The increase in PL DHA correlated significantly with BMI decrease $(r=-0.595, p=0.008)$ and there was a positive correlation of myristate change (14:0) with BMI change (Fig. 3). Serum triglyceride change correlated positively with TG palmitate change and a negative correlation with TG docosahexenoic acid (22:6n-3) change was found (data not shown). The changes in serum triglycerides, serum non-esterified fatty acids and fasting blood glucose levels were not significantly different between n-3 VLCD and VLCD groups (data not shown). 
Table 2. Fatty acid composition in serum lipids before and after the treatment

\begin{tabular}{|c|c|c|c|c|}
\hline \multirow{2}{*}{$\begin{array}{l}\text { Phospholipids } \\
\text { Fatty acid }\end{array}$} & \multicolumn{2}{|c|}{$n-3 \operatorname{VLCD}(n=11)$} & \multicolumn{2}{|c|}{$\operatorname{VLCD}(n=9)$} \\
\hline & Baseline & Day 21 & Baseline & Day 21 \\
\hline $12: 0$ & $0.01 \pm 0.002$ & $0.009 \pm 0.002$ & $0.004 \pm 0.002$ & $0.004 \pm 0.002$ \\
\hline 14:0 & $0.21 \pm 0.02$ & $0.13 \pm 0.002$ & $0.16 \pm 0.009$ & $0.122 \pm 0.009$ \\
\hline $16: 0$ & $31.71 \pm 0.34$ & $34.79 \pm 0.30$ & $31.16 \pm 0.51$ & $33.73 \pm 0.73$ \\
\hline $16: \ln -9$ & $0.14 \pm 0.008$ & $0.19 \pm 0.008$ & $0.14 \pm 0.007$ & $0.13 \pm 0.001$ \\
\hline $16: 1 n-7$ & $0.68 \pm 0.03$ & $0.53 \pm 0.04$ & $0.57 \pm 0.03$ & $0.49 \pm 0.04$ \\
\hline $18: 0$ & $12.57 \pm 0.38$ & $10.29 \pm 0.32$ & $13.18 \pm 0.34$ & $11.23 \pm 0.53$ \\
\hline $18: 1 n-9$ & $8.86 \pm 0.31$ & $8.71 \pm 0.38$ & $9.22 \pm 0.33$ & $9.48 \pm 0.18$ \\
\hline $18: 1 n-7$ & $1.57 \pm 0.07$ & $1.73 \pm 0.05$ & $1.68 \pm 0.05$ & $1.84 \pm 0.005$ \\
\hline $18: 2 n-6$ & $20.86 \pm 0.05$ & $16.68 \pm 0.73$ & $20.11 \pm 0.57$ & $18.67 \pm 0.69$ \\
\hline $18: 3 n-6$ & $0.06 \pm 0.005$ & $0.03 \pm 0.003$ & $0.05 \pm 0.004$ & $0.04 \pm 0.007$ \\
\hline $18: 3 n-3$ & $0.13 \pm 0.008$ & $0.09 \pm 0.005$ & $0.12 \pm 0.008$ & $0.10 \pm 0.011$ \\
\hline $20: 0$ & $0.04 \pm 0.002$ & $0.03 \pm 0.009$ & $0.03 \pm 0.002$ & $0.03 \pm 0.001$ \\
\hline $20: 1$ & $0.11 \pm 0.007$ & $0.11 \pm 0.006$ & $0.12 \pm 0.006$ & $0.12 \pm 0.006$ \\
\hline $20: 2 n-6$ & $0.28 \pm 0.02$ & $0.18 \pm 0.008$ & $0.26 \pm 0.02$ & $0.20 \pm 0.01$ \\
\hline $20: 3 n-6$ & $3.67 \pm 0.22$ & $1.95 \pm 0.06$ & $3.73 \pm 0.20$ & $2.1 . \pm 0.17$ \\
\hline $20: 4 n-6$ & $12.46 \pm 0.47$ & $15.68 \pm 0.94$ & $13.58 \pm 0.74$ & $15.18 \pm 1.01$ \\
\hline $20: 5 n-3$ & $1.05 \pm 0.10$ & $1.68 \pm 0.15^{* * *}$ & $0.77 \pm 0.05$ & $0.63 \pm 0.03$ \\
\hline $22: 5 n-3$ & $0.925 \pm 0.06$ & $1.04 \pm 0.07$ & $0.88 \pm 0.04$ & $0.904 \pm 0.04$ \\
\hline $22: 6 n-3$ & $4.17 \pm 0.27$ & $5.76 \pm 0.22 *$ & $4.07 \pm 0.21$ & $4.52 \pm 0.27$ \\
\hline \multirow{2}{*}{$\begin{array}{l}\text { Triglycerides } \\
\text { Fatty acid }\end{array}$} & \multicolumn{2}{|c|}{$n-3 \operatorname{VLCD}(n=11)$} & \multicolumn{2}{|c|}{$\operatorname{VLCD}(n=9)$} \\
\hline & Baseline & Day 21 & Baseline & Day 21 \\
\hline $12: 0$ & $0.08 \pm 0.01$ & $0.04 \pm 0.004$ & $0.05 \pm 0.007$ & $0.03 \pm 0.006$ \\
\hline $14: 0$ & $1.25 \pm 0.08$ & $0.72 \pm 0.05$ & $0.97 \pm 0.06$ & $0.60 \pm 0.07$ \\
\hline $16: 0$ & $28.46 \pm 0.14$ & $27.35 \pm 0.73$ & $26.57 \pm 0.31$ & $26.17 \pm 0.38$ \\
\hline $16: 1 n-9$ & $0.76 \pm 0.04$ & $0.61 \pm 0.04$ & $0.72 \pm 0.03$ & $0.56 \pm 0.04$ \\
\hline $16: 1 n-7$ & $4.33 \pm 0.12$ & $3.06 \pm 0.20 *$ & $3.64 \pm 0.21$ & $3.06 \pm 0.28$ \\
\hline $18: 0$ & $2.59 \pm 0.07$ & $2.33 \pm 0.09$ & $2.51 \pm 0.19$ & $2.08 \pm 0.11$ \\
\hline $18: \ln -9$ & $38.93 \pm 0.79$ & $39.88 \pm 0.42 *$ & $41.39 \pm 0.49$ & $41.84 \pm 0.79$ \\
\hline $18: \ln -7$ & $2.63 \pm 0.06$ & $2.54 \pm 0.84 *$ & $2.86 \pm 0.07$ & $2.79 \pm 0.09$ \\
\hline $18: 2 n-6$ & $16.24 \pm 0.75$ & $17.14 \pm 0.82$ & $16.39 \pm 0.51$ & $17.19 \pm 0.82$ \\
\hline $18: 3 n-6$ & $0.18 \pm 0.04$ & $0.15 \pm 0.01$ & $0.19 \pm 0.01$ & $0.17 \pm 0.02$ \\
\hline $18: 3 n-3$ & $0.73 \pm 0.05$ & $0.69 \pm 0.05$ & $0.83 \pm 0.34$ & $0.75 \pm 0.03$ \\
\hline $20: 0$ & $0.02 \pm 0.001$ & $0.02 \pm 0.002$ & $0.02 \pm 0.007$ & $0.02 \pm 0.005$ \\
\hline $20: 1$ & $0.18 \pm 0.008$ & $0.14 \pm 0.003$ & $0.19 \pm 0.01$ & $0.17 \pm 0.01$ \\
\hline $20: 2 n-6$ & $0.12 \pm 0.007$ & $0.09 \pm 0.004$ & $0.11 \pm 0.005$ & $0.09 \pm 0.004$ \\
\hline $20: 3 n-6$ & $0.34 \pm 0.05$ & $0.20 \pm 0.001$ & $0.29 \pm 0.02$ & $0.20 \pm 0.02$ \\
\hline $20: 4 n-6$ & $1.58 \pm 0.21$ & $2.13 \pm 0.23$ & $1.60 \pm 0.12$ & $2.10 \pm 0.18$ \\
\hline $20: 5 n-3$ & $0.21 \pm 0.04$ & $0.49 \pm 0.07 * *$ & $0.17 \pm 0.01$ & $0.19 \pm 0.03$ \\
\hline $22: 5 n-3$ & $0.37 \pm 0.03$ & $0.52 \pm 0.04$ & $0.38 \pm 0.03$ & $0.47 \pm 0.03$ \\
\hline $22: 6 n-3$ & $0.76 \pm 0.08$ & $1.22 \pm 0.10^{\#}$ & $0.72 \pm 0.06$ & $0.93 \pm 0.10$ \\
\hline
\end{tabular}

${ }^{*} p<0.1 * p<0.05 * * p<0.01$ in comparison with change in the control group, Values are expressed as means \pm S.E.M. (in mol \%) 


\section{Discussion}

The main finding of the study is that in severely obese females, n-3 PUFA supplementation added to VLCD significantly enhanced BMI loss and reduction of hip circumference. The secondary finding is a significantly higher elevation of serum betahydroxybutyrate in n-3 PUFA supplemented group. Both of these effects occurred despite the fact that the baseline mean BMI for the subjects in the n-3 VLCD group tended to be lower than that for the saline VLCD group, whereas one would expect to observe greater weight loss and higher ketones in heavier subjects given a fixed energy of VLCD.

Similar increase in ketogenesis was found in epileptic patients after using polyunsaturated fatty acids instead of saturated fats during ketogenic diet which lead to a higher increase in beta-hydroxybutyrate (and also in insulin sensitivity) (Fuehrlein et al. 2004). In the above study, the composition of PUFA in the diet was not given. A higher ketosis after diet containing n-3 PUFA in comparison with saturated fats is consistent with the results found in animals (Storlien et al. 1987, Likhodii et al. 2000). In epileptic children treated by ketogenic diet arachidonate and docosahexaenoate in plasma free fatty acids increased simultaneously with beta-hydroxybutyrate elevation (Fraser et al. 2003). The increase in ketogenesis is probably caused by a higher fatty acid oxidation after n-3 PUFA supplementation. In rats, higher beta-oxidation was shown as a mediator of the hypotriglyceridemic effect of the n-3 PUFA (Ukropec et al. 2003). Stimulation of fatty acid oxidation in the liver is caused by the activation of peroxisome proliferator activated receptor alpha (Delarue et al. 2004)

Significant correlation of beta-hydroxybutyrate change with a change in arachidonate content in all serum lipid classes, especially in phospholipids, was demonstrated for the first time. If there is a causal relationship or simultaneous association should be studied further. Compliance to the supplementation was high as indicated by the increase in proportion of EPA and DHA in serum phospholipids and triglycerides.

The enhanced level of arachidonic acid after both treatments could be caused by its higher release from adipose tissue. On the other hand, a lower metabolism of AA after fasting and refeeding was shown by $\mathrm{Qu}$ et al. (1998), who demonstrated significant reduction in total hepatic microsomal AA metabolism in rat liver, concurrently with weight loss and increased beta-hydroxybutyrate levels. In addition to cyclooxygenases and lipooxygenases, cytochrome P450 monooxygenases metabolize AA to compounds which have an important role in the regulation of cellular processes. Fasting has been reported to increase AA accumulation in hepatic neutral and phospholipid pools (LarssonBackstrom et al. 1990). In humans, Phinney et al. (1991) found that arachidonate increased during VLCD, and decreased after finishing the ketogenic diet. Concurrently with AA increase fibrinogen decrease tended to be higher in n-3 VLCD group confirming the previously shown antiinflammatory effect of n-3 PUFA (Browning 2003).

Polyunsaturated fatty acids regulate lipogenic gene expression in different tissues. Clarke and Jump (1994) have demonstrated that dietary fat composition directly affects fatty acid synthase gene expression. As described in rats, a higher decrease of palmitoleic acid in serum triglycerides confirms indirectly the supression of lipogenic genes including fatty acid synthase (Fukuda et al. 1999).

Previous studies in rodents indicated that $n-3$ PUFA enriched diets prevented accumulation of fat in the abdomen (Raclot et al. 1997, Růžičková et al. 2004). The effect of n-3 PUFA (EPA, DHA and mixed fat) on lipogenic genes expression was shown in retroperitoneal fat of rats (Raclot et al. 1997). The replacement of $3 \%$ (wt/wt) of obesity-promoting HF composite diet with EPA/DHA reduced weight gain and reduced the accumulation of epididymal, but not of subcutaneous fat in mice, simultaneously with a depression of tissue cellularity and favorable changes in glucose homeostasis gene activity (Růžičková et al. 2004). The influence of the type of dietary fat on the composition of phospholipids in cellular membrane and possibly also function becomes increasingly important with positive energy balance (Cha and Jones 2000). The effect of n-3 PUFA addition to the diet of obese subjects could be more expressed under conditions of lower energy deficit.

\section{Conclusion}

The addition of n-3 PUFA of fish origin to a very low calorie diet results in a greater BMI loss and hip circumference reduction in severely obese women during an inpatient short-term weight-reducing regimen. Higher increase in beta-hydroxybutyrate was shown in the n-3 group probably due to a higher beta-oxidation of fatty 
acids. Significant correlation of BMI loss with change in phospholipid docosahexaenoic acid level suggests a causal relationship.

\section{Acknowledgements}

This work was supported by the grant of the Czech Ministry of Health NB/7031-3. We express our gratitude to Stephen D. Phinney for helpful comments.

\section{References}

ARVIDSSON E, VIGUERIE N, ANDERSSON I, VERDICH C, LANGIN D, ARNER P: Effects of different hypocaloric diets on protein secretion from adipose tissue of obese women. Diabetes 53: 1966-1971, 2004.

BERRY EM: Who's afraid of n-6 polyunsaturated fatty acids? Methodological considerations for assessing whether they are harmful. Nutr Metab Cardiovasc Dis 11: 181-188, 2001.

BORKMAN M, STORLIEN LH, PAN DA, JENKINS AB, CHISHOLM DJ, CAMPBELL LV: The relation between insulin sensitivity and the fatty acid composition on skeletal muscle phospholipids. $N$ Engl J Med 328: 238244, 1993.

BROWNING LM: N-3 polyunsaturated fatty acids, inflammation and obesity-related disease. Proc Nutr Soc 62: $447-$ 453, 2003.

CHA MC, JONES PJH: Energy restriction dilutes the changes related to dietary fat type in membrane phospholipid fatty acid composition in rats. Metabolism 49: 977-983, 2000.

CLARKE SD, JUMP DB: Dietary polyunsaturated fatty acid regulation of gene transcription. Annu Rev Nutr 14: 83-98, 1994.

CLIFTON PM, NOAKES M, KEOGH JB: Very low-fat (12\%) and high monounsaturated fat (35\%) diets do not differentially affect abdominal fat loss in overweight, nondiabetic women. J Nutr 134: 1741-1745, 2004.

COUET C, DELARUE J, RITZ P, ANTOINE JM, LAMISSE F: Effect of dietary fish oil on body fat mass and basal fat oxidation in healthy adults. Int J Obes 21: 637-643, 1997.

CUNNANE SC, BELZA K, ANDERSON MJ, RYAN MA: Substantial carbon recycling from linoleate into products of de novo lipogenesis occurs in rat liver even under conditions of extreme dietary linoleate deficiency. J Lipid Res 39: 2271-2276, 1998.

CUNNANE SC, RYAN MA, NADEAU CR, BAZINET RP, MUSA-VELOSO K, MCCLOY U: Why is carbon from some polyunsaturates extensively recycled into lipid synthesis? Lipids 38: 477-484, 2003.

DELARUE J, COUET C, COHEN R, BRÉCHOT JF, ANTOINE JM, LAMISSE F: Effects of fish oil on metabolic responses to oral fructose and glucose loads in healthy humans. Am J Physiol 270: E353-E362, 1996.

DELARUE J, LEFOLL C, CORPOREAU C, LUCAS D: N-3 long chain polyunsaturated fatty acids: a nutritional tool to prevent insulin resistance associated to type 2 diabetes and obesity? Reprod Nutr Dev 44: 289-299, 2004.

DUNCOMBE WG: The colorimetric micro-determination of non-esterified fatty acids in plasma. Clin Chim Acta 9: 122-125, 1964.

DURNIN JV, WOMMERSLEY AG: Body fat assessed from total body density and its estimation from skinfold thickness: measurements on 481 men and women aged from 16 to 72 years. Br J Nutr 32, 77-97, 1974.

FELTON CV, STEVENSON JC, GODSLAND IF. Erythrocyte-derived measures of membrane lipid composition in healthy men: associations with arachidonic acid at low to moderate but not high insulin sensitivity. Metabolism 53: 571-577, 2004.

FRASER DD, WHITING S, ANDREW RD, MACDONALD EA, MUSA-VELOSO K, CUNNANE SC: Elevated polyunsaturated fatty acids in blood serum obtained from children on the ketogenic diet. Neurology 60: 10261029, 2003.

FUEHRLEIN BS, RUTENBERG MS, SILVER JN, WARREN MW, THERIAQUE DW, DUNCAN GE, STACPOOLE PW, BRANTLY ML: Differential metabolic effects of saturated versus polyunsaturated fats in ketogenic diets. J Clin Endocrinol Metab 89: 1641-1645, 2004.

FUKUDA H, IRITANI N, SUGIMOTO T, IKEDA H: Transcriptional regulation of fatty acid synthase gene by insulin/glucose, polyunsaturated fatty acid and leptin in hepatocytes and adipocytes in normal and genetically obese rats. Eur J Biochem 260: 505-511, 1999. 
HAINER V, STUNKARD AJ, KUNEŠOVÁ M, PAŘÍZKOVÁ J, ŠTICH V, ALLISON DB: Intrapair resemblance in very low calorie diet induced weight loss in female obese identical twins. Int J Obes Relat Metab Disord 24: 1051-1057, 2000.

KRIKETOS AD, ROBERTSON RM, SHARP TA, DROUGAS H, REED GW, STORLIEN LH, HILL JO: Role of weight loss and polyunsaturated fatty acids in improving metabolic fitness in moderately obese, moderately hypertensive subjects. J Hypertens 19: 1745-54, 2001.

KUNEŠOVÁ M, PHINNEY S, HAINER V, TVRZICKÁ E, ŠTICH V, PAŘÍZKOVÁ J, ŽÁK A, STUNKARD A: The responses of serum and adipose fatty acids to a one-year weight reduction regimen in female obese monozygotic twins. Ann N Y Acad Sci 967: 311-323, 2002a.

KUNEŠOVÁ M, HAINER V, TVRZICKÁ E, PHINNEY SD, ŠTICH V, PAŘÍZKOVÁ J, ŽÁK A, STUNKARD AJ: Assessment of dietary and genetic factors influencing serum and adipose fatty acid composition in obese female identical twins. Lipids 37: 27-32, 2002b.

LARSSON-BACKSTROM C, ARRHENIUS E, SAGGE K, LINDMARK L, PAPROCKI J, SVENSSON L: Sequential changes in lipid metabolism and the fatty acid profile in liver lipids dutiny fasting and sepsis. Cirk Shock $\mathbf{3 0}$ : 331-347, 1990.

LIKHODII SS, MUSA K, MENDONCA A, DELL C, BURNHAM WM, CUNNANE SC. Dietary fat, ketosis, and seizure resistance in rats on the ketogenic diet. Epilepsia 41: 1400-1410, 2000.

LOHMAN T, ROCHE A, MARTOREL R.(eds.) Standardization of Anthropometric Measurements. Human Kinetics Publishers, Champaign, IL. 1989.

LOVEJOY JC, CHAMPAGNE CM, SMITH SR, DELANY JP, BRAY GA, LEFEVRE M, DENKINS YM, ROOD C: Relationship of dietary fat and serum cholesterol ester and phospholipid fatty acids to markers of insulin resistance in men and women with a range of glucose tolerance. Metabolism 50: 86-92, 2001.

MCCLOY U, RYAN MA, PENCHARZ PB, ROSS RJ, CUNNANE SC: A comparison of the metabolism of eighteencarbon 13C-unsaturated fatty acids in healthy women. J Lipid Res 45: 474-485, 2004.

MELOUN M, HILL M, MILITKY J, KUPKA K: Transformation in the PC-aided biochemical data analysis. Clin Chem Lab Med 38: 553-559, 2000.

MELOUN M, MILITKY J, HILL M, BRERETON RG: Crucial problems in regression modelling and their solutions. Analyst 127: 433-450, 2002.

MELOUN M, HILL M, MILITKY J, VRBÍKOVÁ J, STANICKÁ S, ŠKRHA J: New methodology of influential point detection in regression model building for the prediction of metabolic clearance rate of glucose. Clin Chem Lab Med 42: 311-322, 2004.

OLSEN CH: An enzymatic fluorimetric micromethod for the determination of acetoacetate, beta-hydroxybutyrate, pyruvate and lactate. Clin Chim Acta 33: 293-300, 1971.

PAŘÍZKOVÁ J: Body Fat and Physical Fitness. M. Nijhoff, Hague, 1977.

PELIKÁNOVÁ T, KOUHOUT M, VÁLEK J, BAŠE J, KAZDOVÁ L: Insulin secretion and insulin action related to the serum phospholipid fatty acid pattern in healthy men. Metabolism 38, 188-192, 1989.

PHINNEY SD, TANG AB, JOHNSON SB, HOLMAN RT: Reduced adipose 18:3w3 with weight loss by very low calorie dieting. Lipids 25: 798-806, 1990.

PHINNEY SD, DAVIS PG, JOHNSON SB, HOLMAN RT: Obesity and weight loss alter serum polyunsaturated lipids in humans. Am J Clin Nutr 53: 831-838, 1991.

QU W, RIPPE RA, MA J, SCARBOROUGH P, BIAGINI C, FIEDOREK FT, TRAVLOS GS, PARKER C, ZELDIN DC: Nutritional status modulates rat liver cytochrome P450 arachidonic acid metabolism. Mol Pharmacol 54: 504-513, 1998.

RACLOT T, GROSCOLAS R, LANGIN D, FERRE P: Site-specific regulation of gene expression by n-3 polyunsaturated fatty acids in rat white adipose tissues. J Lipid Res 38: 1963-1972, 1997.

RŮŽIČKOVÁ J, ROSSMEISL M, PRAŽÁK T, FLACHS P, ŠPONAROVÁ J, BRYHN M, KOPECKÝ J: Omega-3 polyunsaturated fatty acids of marine origin reduce dietary obesity in mice by affecting cellularity of adipose tissue. Lipids 39: 1177-1185, 2004. 
STORLIEN LH, KRAEGEN EW, CHISHOLM DJ, FORD GL, BRUCE DG, PASCOE WS: Fish oil prevents insulin resistance induced by high-fat feeding in rats. Science 237: 885-888, 1987.

TVRZICKÁ E, VECKA M, STAŇKOVÁ B, ŽÁK A: Analysis of fatty acids in plasma lipoproteins by gas chromatography-flame ionization detection. Quantitative aspects. Anal Chim Acta 465: 337-350, 2002.

UKROPEC J, RESELAND JE, GAŠPERIKOVÁ D, DEMČÁKOVÁ E, MADSEN L, BERGE RK, RUSTAN AC, KLIMEŠ I, DREVON CA, ŠEBÖKOVÁ E: The hypotriglyceridemic effect of dietary n-3 FA is associated with increased beta-oxidation and reduced leptin expression. Lipids 38: 1023-1029, 2003.

VESSBY B, ARO A, SKAFORS E, BERGLUNG L., SALMINEN I, LITHELL H: The risk to develop NIDDM is related to the fatty acid composition of serum cholesterol esters. Diabetes 43: 1353-1357, 1994a.

VESSBY B, TENGBLAD S, LITHELL H: Insulin sensitivity is related to the fatty acid composition of serum lipids and skeletal muscle phospholipids in 70-year-old men. Diabetologia 37: 1044-1050, 1994b.

VIGUERIE N, VIDAL H, ARNER P, HOLST C, VERDICH C, AVIZOU S, ASTRUP A, SARIS WH, MACDONALD IA, KLIMČÁKOVÁ E, CLEMENT K, MARTINEZ A, HOFFSTEDT J, SORENSEN TI, LANGIN D; FOR THE NUTRIENT-GENE INTERACTIONS IN HUMAN OBESITY-IMPLICATIONS FOR DIETARY GUIDELINE (NUGENOB) PROJECT. Adipose tissue gene expression in obese subjects during low-fat and high-fat hypocaloric diets. Diabetologia 48: 123-131, 2005.

\section{Reprint requests}

M. Kunešová, Obesity Management Center, Institute of Endocrinology, Národní 8, 11694 Prague 1, Czech Republic. E-mail: mkunesova@endo.cz,marie.kunesova@1f1.cuni.cz 